\title{
Dimethyl sulfoxide as a strongly coordinating solvent: 3',4'-dihydroxyflavone-Cu(II)-DMSO system case study
}

\author{
Miriama Šimunková, Michal Malček \\ Institute of Physical Chemistry and Chemical Physics, Faculty of Chemical and Food Technology, \\ Slovak University of Technology in Bratislava, Radlinského 9, SK-812 37 Bratislava, Slovak Republic \\ miriama.simunkova@stuba.sk
}

\begin{abstract}
Dimethyl sulfoxide (DMSO) is an aprotic organic solvent widely used in laboratory practice due to its ability to dissolve both polar and nonpolar compounds. However, DMSO is also commonly known as a strongly coordinating solvent, especially towards transition metal containing complexes. In this study, estimation of the coordination ability of DMSO towards the Cu(II) ion was attempted, employing a model system composed of 3' 4 -dihydroxyflavone-Cu(II) complex in the presence of explicit DMSO molecules, using the density functional theory (DFT). Nature of the Cu-DMSO chemical interaction (i.e. Cu-O bonding) was studied within the framework of quantum theory of atoms in molecules (QTAIM). Impact of DMSO coordination on the charge and spin distribution at $\mathrm{Cu}(\mathrm{II})$ ion was inspected using Mulliken population and QTAIM analysis.
\end{abstract}

Keywords: coordination chemistry, Density Functional Theory, DMSO, QTAIM analysis, solvent effect

\section{Introduction}

Anhydrous dimethyl sulfoxide (DMSO) is an aprotic organic solvent widely used in laboratory practice, including important biochemical and biological experiments (Tashrifi et al., 2020; Psomas and Kessissoglou, 2013; Dorotíková et al., 2015; Simunkova et al., 2019; Misuri et al., 2017). It was first prepared by Alexander Saytzeff in 1867 using oxidation of dimethyl sulfide (Saytzeff, 1867). DMSO, an amphipathic molecule composed of a polar domain characterized by a sulfinyl and two nonpolar methyl groups, is able to solubilize a wide variety of polar and nonpolar compounds at high concentrations (De Abreu Costa et al., 2017; Tunçer et al., 2018). The DMSO- $\mathrm{H}_{2} \mathrm{O}$ binary mixture (Sergievskii, Skorobogat'Ko, and Rudakov, 2010; Roy et al., 2011) is a common solvent in experiments involving cell cultures since a small amount of DMSO is well tolerated and does not change the culture viability (Allen et al., 2008; Singh and Ghosh, 2016). In addition, DMSO is well known as a strongly coordinating solvent (Levchenkov et al., 2014; Rancan and Armelao, 2015; Rancan et al., 2019; Patra et al., 2013) Highly polarized $S=O$ double bond has positive and negative charges localized on sulfur and oxygen atoms, respectively (Cioslowski and Surján, 1992). This polarity of the $\mathrm{S}=\mathrm{O}$ double bond is related to the high dielectric constant. With respect to the properties of the coordinated metal, DMSO can bind via either the sulfur or (sterically less hindered) oxygen atom. As reported by Calligaris, the S-bonding is essentially limited to the metal atoms of groups 8-10 (Calligaris, 1999). A decade ago, Díaz-Torres and Alvarez (Diaz-Torres and Alvarez, 2011) attempted to quantify the coordinating character of a series of various solvents based on the probability to find the particular solvent coordinated in the presence of a transition metal. Their search was conducted in the Cambridge Structural Database (CSD), (Allen, 2002) and DMSO was found to be coordinated in $65 \%$ of the searched cases (2038 structures in total) (Diaz-Torres and Alvarez, 2011). Moreover, strong coordination of the DMSO solvent towards transition metals can lead to chemical changes in coordination compounds. For example, Patra et al. (Patra et al., 2013) revealed, using ${ }^{1} \mathrm{H}$ NMR spectroscopy, that Ru complexes with $N$-heterocyclic ligands readily undergo a ligand exchange reaction in DMSO. Recently, Rancan et al. (Rancan and Armelao, 2015; Rancan et al., 2019) pointed out that the use of DMSO affects the synthesis of coordination polymers by blocking some coordination sites. Aside the above mentioned coordination ability, the DMSO solvent can also act as a hydrogen bonding acceptor, as it was reported by Protti and coworkers (Protti et al., 2008)

In our previous studies (Jomová et al., 2019; Šimunková et al., 2020), antioxidant activity of flavonoid-Cu(II) complexes in the DMSO solvent was investigated. It is well known that biological activity of flavonoids can be significantly enhanced in the presence of transition metal ions (in this case cupric ion), forming complex compounds (Kumar and Pandey, 2013; Grazul and Budzisz, 2009; Samsonowicz and Regulska, 2017; Jomová et al., 2019). In general, study of antioxidant activity of flavonoids or other transition metal complexes is often limited by their poor solubility in most assays, thus the use of solvents such as DMSO is required (van Acker et al., 1996). However, strong coordination 


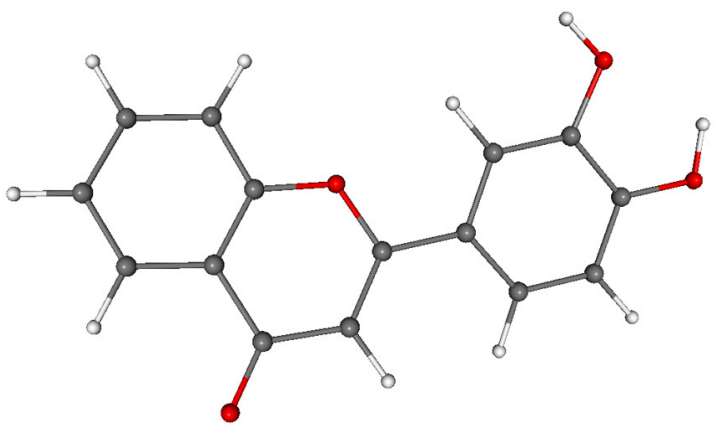

a)

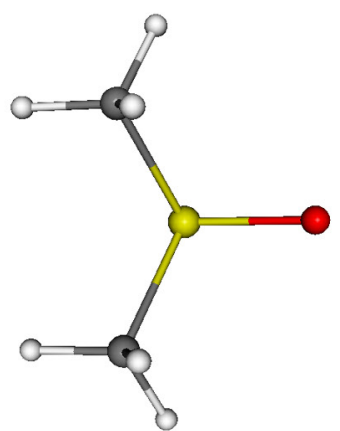

b)

Fig. 1. Scheme of B3LYP/6-311G* optimized DHF (a) and DMSO (b).

affinity of DMSO towards the Cu(II) ion (Rancan et al., 2019) is a problem. Gutmann donor number of DMSO, which is a measure of the strength of solvent as Lewis base, is 29.8 (Gutmann, 1978). For comparison, Gutmann donor numbers of methanol $(\mathrm{MeOH})$ and $\mathrm{H}_{2} \mathrm{O}$ are 19 and 18 , respectively (Gutmann, 1978). To study the DMSO-Cu(II) coordination directly, inclusion of explicit solvent (DMSO) molecules in theoretical calculations is necessary. In this work, 3',4'-dihydroxyflavone-Cu(II) complex in the DMSO solvent from our previous studies (Jomová et al., 2019) was used as a model system. 3',4'-Dihydroxyflavone (DHF) is a polyphenolic compound containing a 2-phenyl-benzo- $\gamma$-pyrone moiety typical for flavonoids (Kumar and Pandey, 2013; Grazul and Budzisz, 2009; Jomová et al., 2019) (Figure 1a). For completeness, optimized structure of DMSO is shown in Figure $1 \mathrm{~b}$.

The paper is organized as follows: computational details are presented at first; then the Results section is subdivided into three parts, where optimized structures, charge density topologies, analysis of bond critical points and impact of coordinated DMSO molecules on the EPR parameters are discussed. At last, the main conclusions of this work are summarized.

\section{Computational details}

Model system DHF-Cu(II) was solvated with two and four molecules of DMSO. In all cases, the $\mathrm{DHF}-\mathrm{Cu}(\mathrm{II})$ system containing protonated as well as deprotonated $\mathrm{OH}$ groups was considered. [Note that the deprotonation of $\mathrm{OH}$ groups of $\mathrm{DHF}$ is denoted with "-2H" superscript throughout the manuscript.] As a reference, $\mathrm{Cu}(\mathrm{II})$ ion solvated with two, four, five and six DMSO molecules was used. Additional reference systems, particularly $\mathrm{Cu}(\mathrm{II})-n \mathrm{H}_{2} \mathrm{O}$ and $\mathrm{Cu}(\mathrm{II})-n \mathrm{MeOH}$ (where $n=5,6$ ) complexes, were selected for comparison purposes only. Water and methanol act like donor solvents coordinating the $\mathrm{Cu}(\mathrm{II})$ ion via oxygen, i.e. in the same way as in case of DMSO. Geometry optimization of all studied systems was performed at the B3LYP (Becke, 1988; Lee, Yang, and Parr, 1988; Becke, 1993; Vosko, Wilk, and Nusair, 1980)/6311G* (Krishnan et al., 1980; McLean and Chandler, 1980) level of theory in the Gaussian09 program package. (Frisch et al., 2009) The computational protocol used here (B3LYP/6-311G*) was chosen in accordance with our previously published results (Šimunková et al., 2020). In our previous study (Šimunková et al., 2020), the use of DFT functionals accounting for dispersion correction (particularly B3LYP-GD3 and B2PLYP) was reported to have only negligible effect on the geometries and energies of $\mathrm{Cu}(\mathrm{II})$-flavonoid complexes compared to B3LYP. The energy-based criterion of SCF convergence was set to $10^{-8}$ Hartree. All systems were treated as doublets using the unrestricted Kohn-Sham formalism. Vibrational analysis was employed to confirm that the optimal geometries correspond to energy minima (i.e. absence of imaginary vibrations). Solvent effects of DMSO were treated via Polarizable Continuum solvent Model (PCM) (Miertus, Scrocco, and Tomasi, 1981; Tomasi, Mennucci, and Cammi, 2005) and Solvent Model based on Density (SMD) (Marenich, Cramer, and Truhlar, 2009) as implemented in the Gaussian09 package.

Quantum Theory of Atoms in Molecules (QTAIM) analysis (Bader, 1990), as implemented in the AIMAll package, (Keith, 2014) was applied for every system under study using the Gaussian09 formatted checkpoint files. QTAIM analysis was employed to evaluate charge populations at particular atoms and to estimate the character of interatomic interactions using properties in the bond critical points (BCP) and delocalization indexes (DI). Visualization of the calculated structures was performed using the Molekel software suite (Flükiger et al., 2002). 


\section{Results and Discussion}

\section{Structure of studied systems}

Optimized geometries of all systems under study are shown in Figures 2 [DHF-Cu- $n$ DMSO $(n=2,4)$ complexes] and 3 [Cu- $n \mathrm{DMSO}(n=2,4,5,6)$ reference systems]. In case of DHF-Cu solvated with two DMSO molecules, the Cu(II) ion has a square planar coordination polyhedron with oxygens in the corners (Figures 2c and 2d). In case of DHF-Cu solvated with four DMSO molecules, the coordination polyhedron of $\mathrm{Cu}(\mathrm{II})$ is a Jahn-Teller distorted octahedron (Figures 2e and 2f). The main difference between the (protonated) DHF-Cu-4DMSO and the (deprotonated) $\mathrm{DHF}^{(-2 \mathrm{H})}-\mathrm{Cu}-4 \mathrm{DMSO}$ system is that the former has one $\mathrm{OH}$ group of $\mathrm{DHF}$ and one DMSO molecule in the axial positions while the latter contains two DMSO molecules in the axial positions. This can be clearly seen from the calculated $\mathrm{Cu}-\mathrm{O}$ bond lengths of the above-mentioned systems. Optimized B3LYP/6-311G* Cu-O bond lengths of all the systems under study are presented in Table 1, including the reference $\mathrm{Cu}-n \mathrm{DMSO}$ systems. As it can be seen from Figure 3 and Table 1, coordination polyhedron of $\mathrm{Cu}(\mathrm{II})$ in $\mathrm{Cu}-2 \mathrm{DMSO}$, $\mathrm{Cu}-4 \mathrm{DMSO}, \mathrm{Cu}-5 \mathrm{DMSO}$, and $\mathrm{Cu}-6 \mathrm{DMSO}$ is linear, square planar, square pyramid, and Jahn-Teller distorted (elongated) octahedron as reported in Rancan et al. (Rancan and Armelao, 2015), respectively. For comparison, a scheme of the optimized $\mathrm{Cu}(\mathrm{II})-n \mathrm{H}_{2} \mathrm{O}$ and $\mathrm{Cu}(\mathrm{II})-n \mathrm{MeOH}$ (where $n=5,6)$ complexes is shown in Figure $\mathrm{S} 1$ in Electronic Supplementary Material (ESI).

From the calculated $\mathrm{Cu}-\mathrm{O}$ bond lengths presented in Table 1 follows that in fully protonated systems, $\mathrm{Cu}-\mathrm{O}$ bonds between $\mathrm{Cu}$ and DMSO molecules are stronger (equatorial bonds being shorter than $2 \AA$ ) than those between $\mathrm{Cu}$ and DHF (equatorial bonds being longer than $2 \AA$ ). On the contrary, in case of deprotonated systems, $\mathrm{Cu}-\mathrm{O}$ bonds between $\mathrm{Cu}$

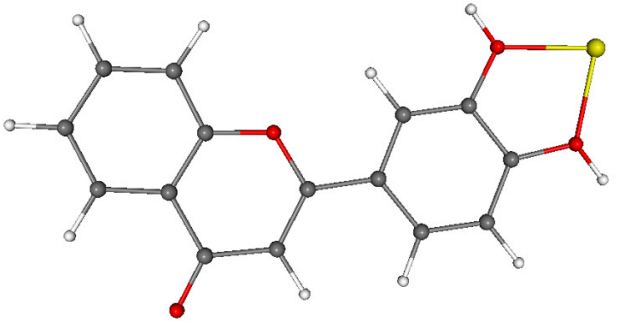

a)

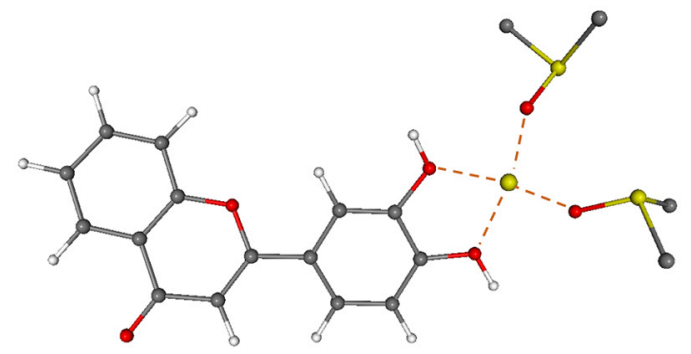

c)

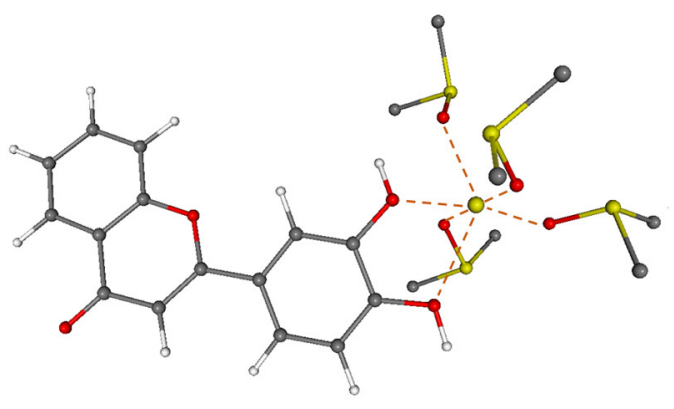

e)

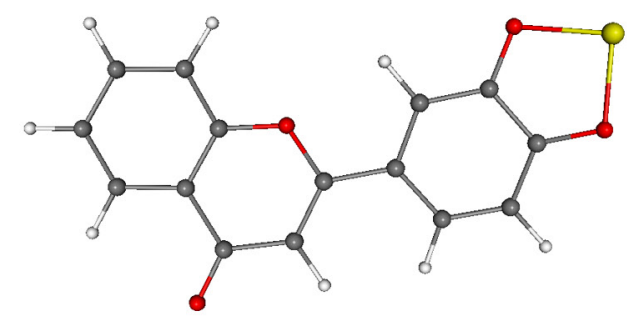

b)

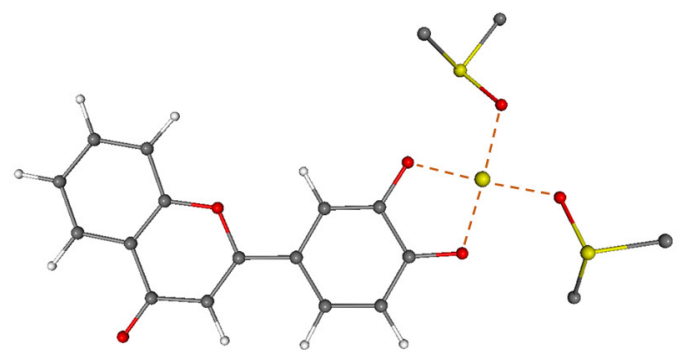

d)

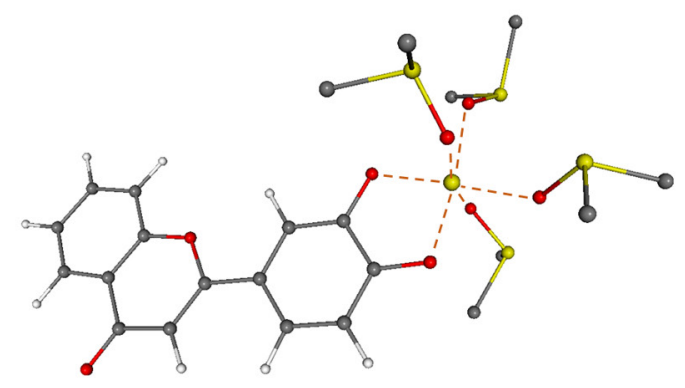

f)

Fig. 2. Scheme of B3LYP/6-311G* optimized DHF-Cu- $n$ DMSO systems: DHF-Cu (a), DHF ${ }^{(-2 H)}-\mathrm{Cu}(\mathrm{b})$, DHF-Cu-2DMSO (c), DHF ${ }^{(-2 H)}$-Cu-2DMSO (d), DHF-Cu-4DMSO (e), DHF ${ }^{(-2 H)}$-Cu-4DMSO (f).

For simplicity, hydrogens of DMSO molecules are omitted. 
and DHF are the stronger ones compared to the Cu-DMSO interaction. Obviously, the presence of $\mathrm{O}-\mathrm{H}$ bonds weakens the binding capacity of DHF's oxygens towards the $\mathrm{Cu}(\mathrm{II})$ ion, leading to stronger interaction of $\mathrm{Cu}(\mathrm{II})$ with DMSO molecules. It is also noteworthy that all equatorial $\mathrm{Cu}-\mathrm{O}$ bonds (either $\mathrm{Cu}-\mathrm{O}^{\mathrm{DHF}}$ or $\mathrm{Cu}-\mathrm{O}^{\mathrm{DMSO}}$ ) in Table 1 have similar lengths in the interval of 1.9-2.1 $\AA$. This finding points out that the coordination of DHF to $\mathrm{Cu}(\mathrm{II})$ is of similar strength than the one of DMSO to $\mathrm{Cu}(\mathrm{II})$. For comparison, equatorial $\mathrm{Cu}-\mathrm{O}$ bond lengths in $\mathrm{Cu}-4 \mathrm{DMSO}$, Cu-5DMSO and $\mathrm{Cu}-$ 6 MDSO are from the interval of 1.9-2.0 $\AA$. [We do not consider the Cu-2DMSO system because it does not represent the DMSO solvation of the $\mathrm{Cu}(\mathrm{II})$ ion. These data are presented only for the sake of completeness.] Our calculated data are in agreement with the average $\mathrm{Cu}-\mathrm{O}$ bond distances in metal sulfoxide complexes $(2.03 \AA$ ) reported by Calligaris (Calligaris, 1999).

In addition, the two solvent models used (i.e. PCM (Miertus, Scrocco, and Tomasi, 1981; Tomasi, Men- nucci, and Cammi, 2005) and SMD (Marenich, Cramer, and Truhlar, 2009)) were compared. Differences in the optimized $\mathrm{Cu}-\mathrm{O}$ bond lengths using either PGM or SMD solvent model are less than $0.1 \AA$, hence they can be considered negligible. However, in case of calculating certain properties, such as solvatochromic shifts (Eilmes, 2014), reaction energy barriers (Miguel et al., 2016), or solvation free energies (Guerard and Arey, 2013), the choice of the solvent model can play a nonnegligible role.

\section{Charge density topology and QTAIM Cu-O bond characteristics}

In the presented work, charge density topology of the studied systems was analyzed using the Mulliken population analysis (Mulliken, 1955) and the Bader's quantum theory of atoms in molecules (QTAIM) (Bader, 1990). Mulliken population analysis (as implemented in Gaussian09) is based on the Roothan's self-consistent field (SCF) LCAO-MO method (Roothaan, 1951), while Bader's QTAIM

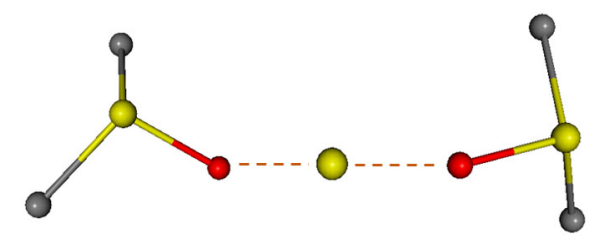

a)

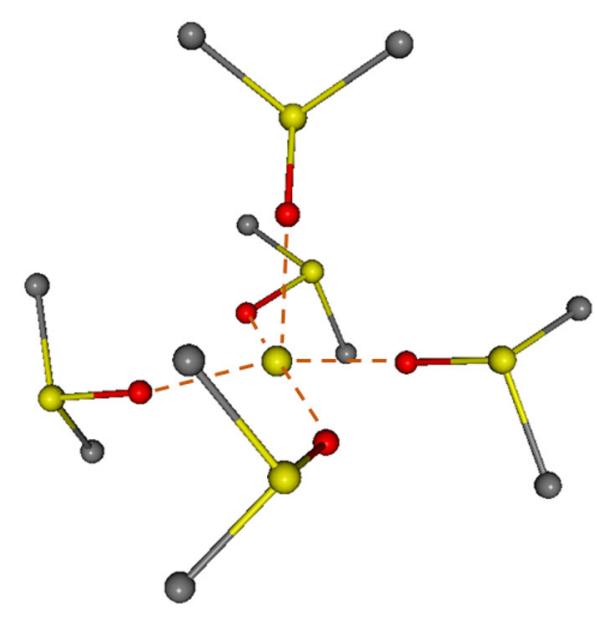

c)

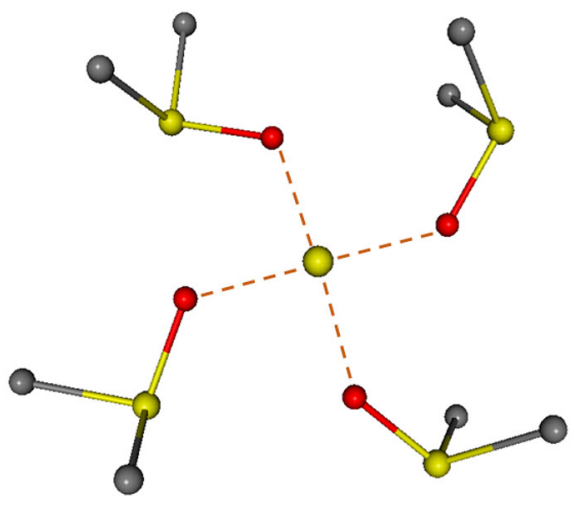

b)

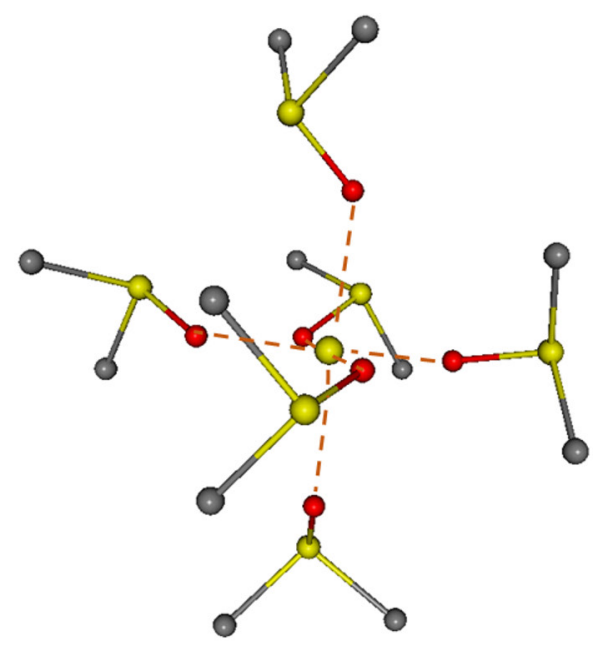

d)

Fig. 3. Scheme of B3LYP/6-311G* optimized Cu- $n$ DMSO reference systems; where $n=2$ (a), $n=4$ (b), $n=5$ (c), $n=6$ (d). For simplicity, hydrogens of DMSO molecules are omitted. 
Tab. 1. Calculated B3LYP/6-311G* $\mathrm{Cu}-\mathrm{O}$ bond lengths of the studied systems using two solvent models (PCM and SMD). Superscripts "E" or "A" stand for equatorial or axial O position, respectively.

\begin{tabular}{|c|c|c|c|}
\hline System & Solvent model & $d\left(\mathrm{Cu}-\mathbf{O}^{\mathrm{DHF}}\right) / \AA$ & $d\left(\mathbf{C u}-\mathbf{O}^{\text {DMSO }}\right) / \AA$ \\
\hline \multirow[t]{2}{*}{ DHF-Cu } & PCM & $2.03^{\mathrm{a}}, 2.03^{\mathrm{a}}$ & \\
\hline & SMD & $2.05,2.06$ & \\
\hline \multirow[t]{2}{*}{$\mathrm{DHF}^{(-2 \mathrm{H})}-\mathrm{Cu}$} & PCM & $1.90,1.89$ & \\
\hline & SMD & $1.90,1.89$ & \\
\hline \multirow[t]{2}{*}{ DHF-Cu-2DMSO } & PCM & $2.01,2.01$ & $1.90,1.89$ \\
\hline & SMD & $2.03,2.03$ & $1.91,1.91$ \\
\hline \multirow[t]{2}{*}{$\mathrm{DHF}^{(-2 \mathrm{H})}-\mathrm{Cu}-2 \mathrm{DMSO}$} & PCM & $1.91,1.92$ & $1.96,1.96$ \\
\hline & SMD & $1.92,1.93$ & $1.96,1.97$ \\
\hline \multirow[t]{2}{*}{ DHF-Cu-4DMSO } & PCM & $2.10^{\mathrm{E}}, 2.65^{\mathrm{A}}$ & $1.94^{\mathrm{E}}, 1.95^{\mathrm{E}}, 1.97^{\mathrm{E}} 2.28^{\mathrm{A}}$ \\
\hline & SMD & $2.09^{\mathrm{E}}, 2.74^{\mathrm{A}}$ & $1.94^{\mathrm{E}}, 1.95,1.96^{\mathrm{E}}, 2.30^{\mathrm{A}}$ \\
\hline \multirow[t]{2}{*}{$\mathrm{DHF}^{(-2 \mathrm{H})}-\mathrm{Cu}-4 \mathrm{DMSO}$} & PCM & $1.94^{\mathrm{E}}, 1.96^{\mathrm{E}}$ & $2.01^{\mathrm{E}}, 2.02^{\mathrm{E}}, 2.48^{\mathrm{A}}, 2.49^{\mathrm{A}}$ \\
\hline & SMD & $1.95^{\mathrm{E}}, 1.97^{\mathrm{E}}$ & $2.01^{\mathrm{E}}, 2.02^{\mathrm{E}}, 2.48^{\mathrm{A}}, 2.48^{\mathrm{A}}$ \\
\hline \multicolumn{4}{|l|}{ Reference } \\
\hline \multirow[t]{2}{*}{$\mathrm{Cu}-2 \mathrm{DMSO}$} & PCM & & $1.82,1.82$ \\
\hline & SMD & & $1.92,1.93$ \\
\hline \multirow[t]{2}{*}{$\mathrm{Cu}-4 \mathrm{DMSO}$} & PCM & & $1.94,1.95,1.95,1.95$ \\
\hline & SMD & & $1.95,1.95,1.96,1.96$ \\
\hline \multirow[t]{2}{*}{ Cu-5DMSO } & PCM & & $1.98^{\mathrm{E}, \mathrm{a}}, 1.98^{\mathrm{E}, \mathrm{a}}, 1.97^{\mathrm{E}, \mathrm{a}}, 1.98^{\mathrm{E}, \mathrm{a}}, 2.27^{\mathrm{A}, \mathrm{a}}$ \\
\hline & SMD & & $1.98^{\mathrm{E}}, 1.98^{\mathrm{E}}, 1.98^{\mathrm{E}}, 1.98^{\mathrm{E}}, 2.26^{\mathrm{A}}$ \\
\hline \multirow[t]{2}{*}{$\mathrm{Cu}-6 \mathrm{DMSO}$} & PGM & & $1.98^{\mathrm{E}, \mathrm{a}}, 1.99^{\mathrm{E}, \mathrm{a}}, 2.00^{\mathrm{E}, \mathrm{a}}, 2.01^{\mathrm{E}, \mathrm{a}}, 2.38^{\mathrm{A}, \mathrm{a}}, 2.42^{\mathrm{A}, \mathrm{a}}$ \\
\hline & SMD & & $1.99^{\mathrm{E}}, 1.99^{\mathrm{E}}, 2.01^{\mathrm{E}}, 2.01^{\mathrm{E}}, 2.37^{\mathrm{A}}, 2.40^{\mathrm{A}}$ \\
\hline
\end{tabular}

${ }^{a}$ B3LYP/6-311G*/PCM values from Šimunková et al. (Šimunková et al., 2020).

analysis is based on the decomposition of molecule into atomic domains (so-called basins) defined as zero-flux surfaces in the gradient vector field of electron density $[\nabla \rho(r)]$. Calculated Mulliken and QTAIM charges $(q)$ at $\mathrm{Cu}(\mathrm{II}), \mathrm{DHF}$, and DMSO moieties are presented in Table 2 which shows that both Mulliken and QTAIM partial charges at $\mathrm{Cu}$ are from the interval of 1.2-1.4 $e$. Charge transfer from the $\mathrm{Cu}(\mathrm{II})$ ion to the originally electroneutral moieties DHF and DMSO is nearly equivalent in fully protonated systems, i.e. partial charges at DHF and DMSO molecules are similar (around $0.2 e$ ). On the other hand, in case of systems containing deprotonated DHF, charge transfer from $\mathrm{Cu}$ to the $\mathrm{DHF}^{(-2 \mathrm{H})}$ moiety is larger (around $0.5 e$ ) than to the DMSO molecule (around $0.15 e$ ). This result is in agreement with the above reported $\mathrm{Cu}-\mathrm{O}$ bond lengths (see Table 1), i.e. weaker coordination of DMSO to $\mathrm{Cu}$ in the presence of deprotonated DHF than in the presence of protonated DHF.

Partial charges of DMSO molecules in all studied systems (naturally) decrease with respect to their increasing number, from around $0.3 e$ in $\mathrm{Cu}$ 2DMSO up to 0.15 or $0.05 e$ in $\mathrm{Cu}-6 \mathrm{DMSO}$ (equatorial or axial position, respectively) (Table 2). A similar decrease of charge transfer from DMSO to a metal atom (particularly Li) has been reported for $\left[\mathrm{Li}(\mathrm{DMSO})_{\mathrm{n}}\right]^{+}$clusters (Sládek et al., 2011). Herein, the Mulliken population analysis did not provide correct nearly-equivalent values of the DMSO partial charges, $c f$. e.g. Mulliken $q(\mathrm{DMSO})$ values of 0.26 and $0.17 e$ and QTAIM $q(\mathrm{DMSO})$ values of 0.23 and $0.23 e$ for the DHF-Cu-2DMSO system.

Additional information about the character of chemical bonds can be obtained from the analysis of bond critical points (BCPs). Bader has described several types of critical points, among them BCP as a saddle point of electron density between two atoms forming a chemical bond (Bader, 1990). Nature (or strength) of the studied chemical bond can be estimated via properties in the BCP, such as charge density in BCP and its Laplacian. Another useful parameter is the delocalization index (DI) (Bader and Stephens, 1975) which provides a quantitative measure of electrons sharing between the two atoms (Fradera, Austen, and Bader, 1999). BCP charge densities $\left(\rho_{\mathrm{BCP}}\right)$, Laplacians $\left(\Delta \rho_{\mathrm{BCP}}\right)$ and DIs of $\mathrm{Cu}-\mathrm{O}$ bonds in the studied systems are presented in Table 3.

BCP characteristics presented in Table 3 are in overall agreement with the optimized $\mathrm{Cu}-\mathrm{O}$ bond lengths reported in the previous section. In case 
Tab. 2. Mulliken and QTAIM charges $(q)$ at $\mathrm{Cu}, \mathrm{DMSO}$ and DHF moieties calculated at the B3LYP/6-311G*/ PCM level of theory. Superscripts "E" or "A" indicate position (equatorial or axial, respectively) of the DMSO molecule.

\begin{tabular}{|c|c|c|c|c|}
\hline System & & $q(\mathrm{DHF}) / e$ & $q(\mathrm{Cu}) / e$ & $q(\mathrm{DMSO}) / e$ \\
\hline \multirow[t]{2}{*}{ DHF-Cu } & Mulliken & 0.72 & 1.28 & \\
\hline & QTAIM & 0.74 & $1.26^{\mathrm{a}}$ & \\
\hline \multirow[t]{2}{*}{$\mathrm{DHF}^{(-2 \mathrm{H})}-\mathrm{Cu}$} & Mulliken & -1.22 & 1.22 & \\
\hline & QTAIM & -1.19 & 1.19 & \\
\hline \multirow[t]{2}{*}{ DHF-Cu-2DMSO } & Mulliken & 0.21 & 1.36 & $0.26,0.17$ \\
\hline & QTAIM & 0.20 & 1.34 & $0.23,0.23$ \\
\hline \multirow[t]{2}{*}{$\mathrm{DHF}^{(-2 \mathrm{H})}-\mathrm{Cu}-2 \mathrm{DMSO}$} & Mulliken & -1.51 & 1.23 & $0.14,0.14$ \\
\hline & QTAIM & -1.52 & 1.25 & $0.14,0.14$ \\
\hline \multirow[t]{2}{*}{ DHF-Cu-4DMSO } & Mulliken & 0.16 & 1.39 & $0.16^{\mathrm{E}}, 0.16^{\mathrm{E}}, 0.07^{\mathrm{E}}, 0.06^{\mathrm{A}}$ \\
\hline & QTAIM & 0.08 & 1.33 & $0.17^{\mathrm{E}}, 0.18^{\mathrm{E}}, 0.18^{\mathrm{E}}, 0.08^{\mathrm{A}}$ \\
\hline \multirow[t]{2}{*}{$\mathrm{DHF}^{(-2 \mathrm{H})}-\mathrm{Cu}-4 \mathrm{DMSO}$} & Mulliken & -1.78 & 1.39 & $0.10^{\mathrm{E}}, 0.11^{\mathrm{E}}, 0.10^{\mathrm{A}}, 0.09^{\mathrm{A}}$ \\
\hline & QTAIM & -1.56 & 1.29 & $0.11^{\mathrm{E}}, 0.11^{\mathrm{E}}, 0.03^{\mathrm{A}}, 0.03^{\mathrm{A}}$ \\
\hline \multicolumn{5}{|l|}{ Reference } \\
\hline \multirow[t]{2}{*}{$\mathrm{Cu}-2 \mathrm{DMSO}$} & Mulliken & & 1.36 & $0.36,0.28$ \\
\hline & QTAIM & & 1.39 & $0.30,0.32$ \\
\hline \multirow[t]{2}{*}{$\mathrm{Cu}-4 \mathrm{DMSO}$} & Mulliken & & 1.35 & $0.27,0.24,0.08,0.06$ \\
\hline & QTAIM & & 1.31 & $0.17,0.18,0.17,0.17$ \\
\hline \multirow[t]{2}{*}{ Cu-5DMSO } & Mulliken & & 1.38 & $0.13^{\mathrm{E}}, 0.15^{\mathrm{E}}, 0.15^{\mathrm{E}}, 0.14^{\mathrm{E}}, 0.06^{\mathrm{A}}$ \\
\hline & QTAIM & & 1.33 & $0.15^{\mathrm{E}}, 0.16^{\mathrm{E}}, 0.15^{\mathrm{E}}, 0.16^{\mathrm{E}}, 0.06^{\mathrm{A}}$ \\
\hline \multirow[t]{2}{*}{$\mathrm{Cu}-6 \mathrm{DMSO}$} & Mulliken & & 1.38 & $0.11^{\mathrm{E}}, 0.14^{\mathrm{E}}, 0.13^{\mathrm{E}}, 0.13^{\mathrm{E}}, 0.05^{\mathrm{A}}, 0.07^{\mathrm{A}}$ \\
\hline & QTAIM & & 1.35 & $0.14^{\mathrm{E}}, 0.15^{\mathrm{E}}, 0.14^{\mathrm{E}}, 0.14^{\mathrm{E}}, 0.04^{\mathrm{A}}, 0.05^{\mathrm{A}}$ \\
\hline
\end{tabular}

aB3LYP/6-311G*/PCM values from Šimunková et al. (Šimunková et al., 2020).

Tab. 3. Calculated B3LYP/6-311G*/PCM QTAIM BCP characteristics (charge density $\rho_{\mathrm{BCP}}$, Laplacian $\Delta \rho_{\mathrm{BCP}}$ and delocalization index DI) of $\mathrm{Cu}-\mathrm{O}$ bonds in the studied systems. Due to the similar nature (or length) of the particular equatorial or axial $\mathrm{Cu}-\mathrm{O}$ bonds (Table 1), only average values are presented. Superscripts "E" or "A" stand for equatorial or axial O position, respectively, and superscripts "DHF" and "DMSO" indicate the O containing molecule (moiety).

\begin{tabular}{|c|c|c|c|}
\hline System & $\rho_{\mathrm{BCP}}(\mathbf{C u}-\mathbf{O}) / \mathrm{bohr}^{-3}$ & $\Delta \rho_{\mathrm{BCP}}(\mathrm{Cu}-\mathrm{O}) / \mathrm{bohr}^{-5}$ & $\mathrm{DI}(\mathrm{Cu}-\mathrm{O}) /-$ \\
\hline DHF-Cu ${ }^{\mathrm{a}}$ & $0.07^{\mathrm{E}, \mathrm{DHF}}$ & $0.37^{\mathrm{E}, \mathrm{DHF}}$ & $0.35^{\mathrm{E}, \mathrm{DHF}}$ \\
\hline $\mathrm{DHF}^{(-2 \mathrm{H})}-\mathrm{Cu}$ & $0.10^{\mathrm{E}, \mathrm{DHF}}$ & $0.54^{\mathrm{E}, \mathrm{DHF}}$ & $0.62^{\mathrm{E}, \mathrm{DHF}}$ \\
\hline DHF-Cu-2DMSO & $0.07^{\mathrm{E}, \mathrm{DHF}}, 0.10^{\mathrm{E}, \mathrm{DMSO}}$ & $0.40^{\mathrm{E}, \mathrm{DHF}}, 0.54^{\mathrm{E}, \mathrm{DMSO}}$ & $0.32^{\mathrm{E}, \mathrm{DHF}}, 0.52^{\mathrm{E}, \mathrm{DMSO}}$ \\
\hline $\mathrm{DHF}^{(-2 \mathrm{H})}-\mathrm{Cu}-2 \mathrm{DMSO}$ & $0.10^{\mathrm{E}, \mathrm{DHF}}, 0.08^{\mathrm{E}, \mathrm{DMSO}}$ & $0.50^{\mathrm{E}, \mathrm{DHF}}, 0.45^{\mathrm{E}, \mathrm{DMSO}}$ & $0.51^{\mathrm{E}, \mathrm{DHF}}, 0.40^{\mathrm{E}, \mathrm{DMSO}}$ \\
\hline DHF-Cu-4DMSO & $\begin{array}{l}0.06^{\mathrm{E}, \mathrm{DHF}}, 0.02^{\mathrm{A}, \mathrm{DHF}} \\
0.08^{\mathrm{E}, \mathrm{DMSO}}, 0.04^{\mathrm{A}, \mathrm{DMSO}}\end{array}$ & $\begin{array}{l}0.29^{\mathrm{E}, \mathrm{DHF}}, 0.07^{\mathrm{A}, \mathrm{DHF}} \\
0.46^{\mathrm{E}, \mathrm{DMSO}}, 0.17^{\mathrm{A}, \text { DMSO }}\end{array}$ & $\begin{array}{l}0.26^{\mathrm{E}, \mathrm{DHF}}, 0.07^{\mathrm{A}, \mathrm{DHF}} \\
0.42^{\mathrm{E}, \mathrm{DMSO}}, 0.18^{\mathrm{A}, \mathrm{DMSO}}\end{array}$ \\
\hline $\mathrm{DHF}^{(-2 \mathrm{H})}-\mathrm{Cu}-4 \mathrm{DMSO}$ & $\begin{array}{l}0.09^{\mathrm{E}, \mathrm{DHF}} \\
0.07^{\mathrm{E}, \mathrm{DMSO}}, 0.02^{\mathrm{A}, \text { DMSO }}\end{array}$ & $\begin{array}{l}0.45^{\mathrm{E}, \mathrm{DHF}} \\
0.38^{\mathrm{E}, \mathrm{DMSO}}, 0.07^{\mathrm{A}, \mathrm{DMSO}}\end{array}$ & $\begin{array}{l}0.46^{\mathrm{E}, \mathrm{DHF}} \\
0.34^{\mathrm{E}, \mathrm{DMSO}}, 0.12^{\mathrm{A}, \mathrm{DMSO}}\end{array}$ \\
\hline \multicolumn{4}{|l|}{ Reference } \\
\hline Cu-2DMSO & $0.12^{\mathrm{E}}$ & $0.68^{\mathrm{E}}$ & $0.62^{\mathrm{E}}$ \\
\hline $\mathrm{Cu}-4 \mathrm{DMSO}$ & $0.08^{\mathrm{E}}$ & $0.46^{\mathrm{E}}$ & $0.42^{\mathrm{E}}$ \\
\hline Cu-5DMSO & $0.08^{\mathrm{E}}, 0.04^{\mathrm{A}}$ & $0.42^{\mathrm{E}}, 0.17^{\mathrm{A}}$ & $0.39^{\mathrm{E}}, 0.19^{\mathrm{A}}$ \\
\hline $\mathrm{Cu}-6 \mathrm{DMSO}$ & $0.06^{\mathrm{E}}, 0.03^{\mathrm{A}}$ & $0.33^{\mathrm{E}}, 0.12^{\mathrm{A}}$ & $0.31^{\mathrm{E}}, 0.14^{\mathrm{A}}$ \\
\hline
\end{tabular}

${ }^{\text {aB } 3 L Y P / 6-311 G * / P C M ~ v a l u e s ~ f r o m ~ S ̌ i m u n k o v a ́ ~ e t ~ a l . ~(S ̌ i m u n k o v a ́ ~ e t ~ a l . ~ 2020) . ~}$ 
of fully protonated systems, stronger interaction was found between $\mathrm{Cu}$ and DMSO compared to the $\mathrm{Cu}-\mathrm{DHF}$ bond ( $\rho_{\mathrm{BCP}}$ and DI values in Table 3). Such strong coordination can play a key role in ligand replacement reaction when studying various transition metal complexes as competitive reaction between a ligand and DMSO (Sudo et al., 2012). On the contrary, in systems containing deprotonated DHF moiety, the $\mathrm{Cu}-\mathrm{O}$ bond between $\mathrm{Cu}$ and $\mathrm{DHF}^{(-2 \mathrm{H})}$ is stronger than that between $\mathrm{Cu}$ and the DMSO molecule/molecules. Coordination bonds formed between $\mathrm{Cu}$ and oxygens in the equatorial positions have DI values in the interval of 0.3-0.5 (Table 3), indicating a coordination bond equal in strength to nearly half of a single covalent bond (Fradera, Austen, and Bader, 1999). Bond interactions between $\mathrm{Cu}$ and oxygens in the axial positions are, naturally, significantly weaker (DI values below 0.2).

For comparison, BCP parameters and DI values of $\mathrm{Cu}-n \mathrm{DMSO}$ systems are shown in Table 3 as well. These values are comparable to those for $\mathrm{Cu}-n \mathrm{H}_{2} \mathrm{O}$ and $\mathrm{Cu}-n \mathrm{MeOH}(n=5,6)$ presented in Table S1. Thus, coordination of the $\mathrm{Cu}(\mathrm{II})$ ion with DMSO solvent can be assumed to be of similar nature as that of water or methanol molecules.

\section{Impact of explicitly included DMSO molecules on spectroscopic parameters}

As shown in the previous section, coordination of $\mathrm{Cu}$ with DMSO molecules affects the localization of charge density in the studied systems. Subsequently, such changes can possibly affect the properties directly derived from charge (or spin) density. For example, Almeida and Ramalho (de Almeida et al., 2011) reported the effect of explicitly included solvent molecules (pyridine, in particular) on the UV-Vis-NIR and EPR parameters of $\mathrm{Cu}(\text { acac })_{2}$ complex. Also, a comparison of EPR and UVVis spectra of DHF-Cu (molar ratio 1:2) system measured in DMSO (experiments taken from Jomová et al. ${ }^{22}$ ) and in $\mathrm{MeOH}$ (our results presented in Figure S2) prove the existence of such an effect. Stronger coordination of $\mathrm{DHF}$ to $\mathrm{Cu}(\mathrm{II})$ in $\mathrm{MeOH}$ compared to that in DMSO is documented by the higher absorbance band at $410 \mathrm{~nm}$ (see Figure $\mathrm{S} 2 \mathrm{a})$. In case of the EPR spectrum, only small changes were observed for the g-value but there is a non-negligible shift in the A-value of $\mathrm{Cu}$ (II) (115 Gauss in DMSO and 102 Gauss in MeOH, see Figure S2b). This is in agreement with the results of Almeida and Ramalho (de Almeida et al., 2011) who reported the hyperfine coupling constant to be more solvent-dependent than the g-tensor.

With respect to the above statement, the impact of explicit inclusion of DMSO molecules on the calculation of EPR parameters, particularly the hyperfine coupling constant, was studied. In the non-relativistic framework, the isotropic hyperfine coupling constant (HFC) is limited to the Fermi contact interaction. (Fermi, 1930). However, it has to be mentioned that, especially in case of heavy elements containing compounds, the inclusion of spin-orbit coupling contribution as well as the relativistic effects are crucial for proper treatment of the HFC constant (Malček et al., 2015; Malkin et al., 2006, 2011; Neese, 2003; Autschbach, 2014; Haase et al., 2018). However, for comparison purposes and

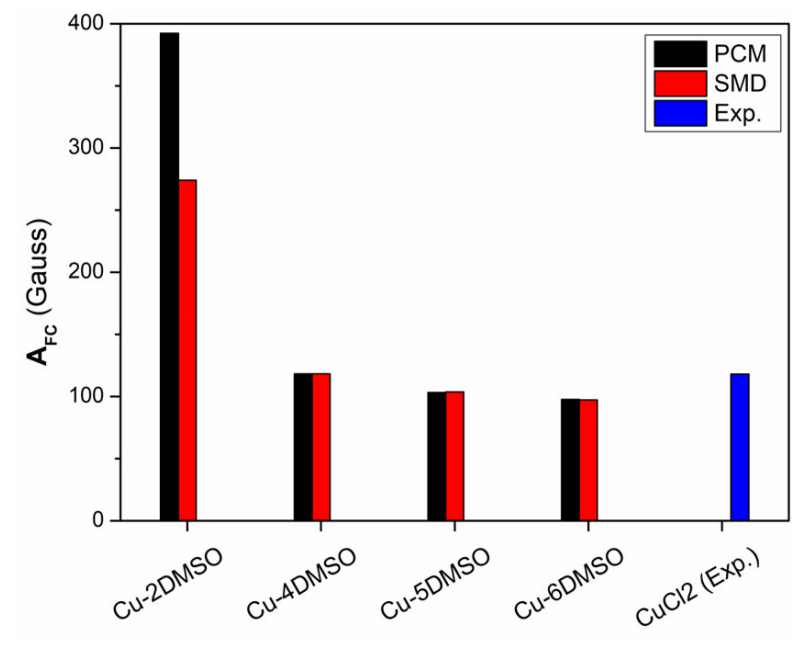

b)

Fig. 4. Comparison of calculated (non-relativistic B3LYP/6-311G*) and experimentally obtained isotropic Fermi contact coupling constants $\left(\mathrm{A}_{\mathrm{FC}}\right)$ of $\mathrm{Cu}$ in the DHF-Cu- $n$ DMSO (a) and Cu- $n$ DMSO (b) systems. Superscript “-2H” indicates deprotonated DHF moiety. Experimental values are taken from Jomová et al. (Jomová et al., 2019). 
for the sake of simplicity, only the non-relativistic limit of HFC (i.e. Fermi contact interaction) was considered here. A comparison of the calculated B3LYP/6-311G* non-relativistic and experimentally obtained (Jomová et al., 2019) isotropic Fermi contact coupling constants $\left(\mathrm{A}_{\mathrm{FC}}\right)$ of the studied systems is shown in Figure 4. (Note that absolute $A_{\mathrm{FC}}$ values are presented even though the calculated $\mathrm{A}_{\mathrm{FC}}$ values are negative, corresponding to the positive spin density at $\mathrm{Cu}$.). As it can be seen from Figure $4 \mathrm{a}$, inclusion of at least two explicit DMSO molecules into the DHF-Cu system significantly improves the agreement between the EPR experiment and theory. The inclusion of solvent model only (either PCM or SMD) into the DFT calculations is not sufficient to obtain qualitative agreement with the EPR experiment. If there are explicit DMSO molecules included, similar results are provided by the two different solvent models (PCM and SMD).

In case of Cu- $n$ DMSO systems, an experimental $\mathrm{A}_{\mathrm{FC}}$ value of $\mathrm{CuCl}_{2}$ in DMSO (Jomová et al., 2019) was used as a reference because it basically represents the $\mathrm{Cu}$ (II) ion solvated with DMSO. As it was already mentioned in the previous sections, the Cu-2DMSO system is not robust enough to properly mimic the DMSO-solvated $\mathrm{Cu}(\mathrm{II})$ ion, see the overestimated $A_{F C}$ value in Figure $4 b$. On the contrary, $A_{F C}$ values of Cu-4DMSO, Cu-5DMSO and Cu-6DMSO are in quantitative agreement with the experimental $\mathrm{A}_{\mathrm{FC}}$ values of $\mathrm{CuCl}_{2}$ in DMSO (Jomová et al., 2019) (Figure 4b). Overall, the results presented in this section further confirm that the strong coordinating ability of the DMSO solvent plays a non-negligible role in the spectroscopic measurements, such as EPR in a frozen solution.

\section{Conclusions}

In the presented work, coordination ability of the DMSO solvent towards the $\mathrm{Cu}(\mathrm{II})$ ion was studied using model system DHF-Cu(II)- $n$ DMSO (where $n=2,4$ ). The obtained results (calculated $\mathrm{Cu}-\mathrm{O}$ bond lengths, BCP characteristics and DIs) have confirmed the strong coordination of the $\mathrm{Cu}(\mathrm{II})$ ion with DMSO molecules, similar to the interaction of $\mathrm{Cu}(\mathrm{II})$ with the DHF molecule (Jomová et al., 2019) or to the water-Cu coordination in $\mathrm{Cu}-5 \mathrm{H}_{2} \mathrm{O}$ and $\mathrm{Cu}-6 \mathrm{H}_{2} \mathrm{O}$ complexes (Malček et al., 2015). In case of fully protonated model system DHF-Cu(II)- $n$ DMSO, interaction between the $\mathrm{Cu}$ and DMSO molecules is stronger than that between $\mathrm{Cu}$ and DHF, while in case of deprotonated system $\mathrm{DHF}^{(-2 \mathrm{H})}-\mathrm{Cu}(\mathrm{II})-n \mathrm{DMSO}$ it is vice versa. Based on these results, a probability of ligand replacement in the DMSO solution of metal complexes can be assumed because DMSO can act as a competitive ligand. Moreover, it was shown that strong coordination of DMSO towards the $\mathrm{Cu}(\mathrm{II})$ ion can also affect the EPR spectroscopic parameters such as the Fermi contact coupling. In case of non-relativistic DFT calculations of the Fermi contact coupling constants, an inclusion of explicit DMSO molecules significantly improved the agreement between the EPR experiment and theory.

\section{Supporting Information}

Figure S1 Scheme of B3LYP/6-311G*/PCM optimized reference systems; where $\mathrm{Cu}(\mathrm{II})-5 \mathrm{H}_{2} \mathrm{O}$ (a), $\mathrm{Cu}(\mathrm{II})-6 \mathrm{H}_{2} \mathrm{O} \quad$ (b), $\mathrm{Cu}(\mathrm{II})-5 \mathrm{MeOH} \quad$ (c), $\mathrm{Cu}(\mathrm{II})-$ $6 \mathrm{MeOH}(\mathrm{d})$.

Figure S2 a) Black line: UV-Vis spectrum of DHF dissolved in methanol, $\mathrm{c}=1.10^{-3} \mathrm{M}$; blue line: $\mathrm{UV}-\mathrm{V}$ is spectra of DHF-Cu(II) (molar ratio $=2: 1$ ) system measured in methanol b) EPR spectrum of DHF-Cu(II) (molar ratio $=2: 1)$ system dissolved in methanol measured at $120 \mathrm{~K}$ (experimental parameters: $\mathrm{g}_{\perp}=2,10 \mathrm{~g}_{\|}=2,42 \mathrm{~A}_{\|}=102$ Gauss).

Table S1 Calculated B3LYP/6-311G*/PGM Cu-O bond lengths $d$, charge densities $\rho_{\mathrm{BCP}}$, Laplacians $\Delta \rho_{\mathrm{BCP}}$ and delocalization indexes DI of $\mathrm{Cu}(\mathrm{II})$ $n \mathrm{H}_{2} \mathrm{O}$ and $\mathrm{Cu}(\mathrm{II})-n \mathrm{MeOH}$ systems (where $n=5,6$ ). Superscripts "E" or "A" stand for average values of equatorial or axial $\mathrm{Cu}-\mathrm{O}$ bonds, respectively.

Table S2 Mulliken and QTAIM charges $(q)$ at $\mathrm{Cu}, \mathrm{H}_{2} \mathrm{O}$ and $\mathrm{MeOH}$ moieties calculated at the B3LYP/6-311G*/PCM level of theory. Superscripts "E" or "A" indicate the position (equatorial or axial, respectively) of $\mathrm{H}_{2} \mathrm{O}$ or $\mathrm{MeOH}$ molecules.

\section{Acknowledgement}

This work received financial support from the Slovak Grant Agencies APVV (contracts No. APVV-15-0079 and APVV-19-0087) and VEGA (contracts No. 1/0139/20, 1/0466/18 and 1/0482/20) and the Slovak University of Technology (Young Researcher Grant - FLAVMET, M. Šimunková and Excellent Team of Young Researchers CUSPK). MM is also grateful to the HPC center at the Slovak University of Technology in Bratislava, which is a part of the Slovak Infrastructure of High Performance Computing (SIVVP project, ITMS code 26230120002, funded by European region development funds) for the computational time and resources made available. To all financing sources the authors are greatly indebted.

Conflict of Interest: The authors declare that they have no conflict of interest.

\section{References}

Abreu CD, Ottoni MHG, Dos Santos MG et al. (2017) Molecules 22: 1-10.

Acker SABE van, de Groot MJ, van der Berg JD et al. (1996) Chem. Res. Toxicol. 9: 1305-1312. 
Allen FH (2002) Acta Crystallographica Section B: Structural Science 58: 380-388.

Allen MJ, Boyce JP, Trentalange TM et al. (2008) Biotechnology and Bioengineering 100: 1193-1204.

Almeida de KJ, Ramalho TC, Rinkevicius R et al. (2011) J. Phys. Chem. A 115: 1331-1339.

Autschbach J (2014) Phil. Trans. R. Soc. A 372: 20120489.

Bader RFW (1990) Atoms in Molecules: A Quantum Theory. Oxford: Oxford University Press.

Bader RFW, Stephens ME (1975) J. Am. Chem. Soc. 97: 7391-7399.

Becke AD (1988) Phys. Rev. A 38: 3098-3100.

Becke AD (1993) The Journal of Chemical Physics 98: 5648-5652.

Calligaris M (1999) Croatica Chemica Acta 72: 147-169.

Cioslowski J, Surján PR (1992) Journal of Molecular Structure: THEOCHEM 255: 9-33.

Diaz-Torres R, Alvarez S (2011) Dalton Transactions 40: 10742-10750.

Dorotíková S, Kožǐšková J, Malček M et al. (2015) Journal of Inorganic Biochemistry 150: 160-73.

Eilmes A (2014) Theoretical Chemistry Accounts 133: 1538.

Fermi E (1930) Z. Phys. 60: 320.

Flükiger P, Lüthi HP, Portmann S, Weber J (2002) “'MOLEKEL 4.3.' Swiss Center for Scientific Computing: Manno, Switzerland.

Fradera X, Austen AM, Bader RFW (1999) J. Phys. Chem. A 103: 304-314.

Frisch MJ, Trucks GW, Schlegel HB, Scuseria GE et al. (2009) "Gaussian 09, Revision D.01." Gaussian, Inc., Wallingford CT.

Grazul M, Budzisz E (2009) Coord. Chem. Rev. 253: 2588-2598.

Guerard JJ, Arey JS (2013) Journal of Chemical Theory and Computation 9: 5046-5058.

Gutmann V (1978) The Donor-Acceptor Approach to Molecular Interactions. New York: Springer US.

Haase PAB, Repisky M, Komorovsky S et al. (2018) Chemistry - A European Journal 24: 5124-5133.

Jomová K, Hudecova L, Lauro P et al. (2019) Molecules 24: 4335 .

Keith AT "AIMAll, Version 14.04.17; TK Gristmill Software: Overland Park, KS, 2014 (Aim.Tkgristmill. Com)."

Krishnan R, Binkley JS, Seeger R et al. (1980) J. Chem. Phys. 72: 650-654.

Kumar S, Pandey KA (2013) The Scientific World Journal, 162750 .

Lee Ch, Yang W, Parr GR (1988) Phys. Rev. B 37: $785-789$.

Levchenkov SI, Hcherbakov IN, Popov LD et al. (2014) Russian Journal of Coordination Chemistry 40: 523-530.

Malček M, Bučinský L, Valko M et al. (2015) Journal of Molecular Modeling 21: 237.

Malkin E, Malkin I, Malkina OL et al. (2006) Phys. Chem. Chem. Phys. 8: 4079-4085.

Malkin E, Repiský M, Komorovský S et al. (2011) Journal of Chemical Physics 134: 044111.

Marenich VA, Cramer ChJ, Truhlar DG (2009) Journal of Physical Chemistry B 113: 6378-6396.

McLean AD, Chandler GS (1980) J. Chem. Phys. 72: 5639-5648.
Miertus S, Scrocco E, Tomasi J (1981) Chem. Phys. 55: $117-129$

Miguel ELM, Santos CIL, Silva CM et al. (2016) Journal of the Brazilian Chemical Society 27: 2055-2061.

Misuri L, Cappiello M, Balestri F et al. (2017) Journal of Enzyme Inhibition and Medicinal Chemistry 32: 1152-1158.

Mulliken RS (1955) The Journal of Chemical Physics 23: 1833.

Neese F (2003) J. Chem. Phys. 118: 3939-3948.

Patra M, Pierroz VA et al. (2013) Chemistry - A European Journal 19: 14768-14772.

Protti S, Mezzetti A, Cornard JP et al. (2008) Chemical Physics Letters 467: 88-93.

Psomas G, Kessissoglou DP (2013) Dalton Transactions 42: 6252-6276.

Rancan M, Armelao L (2015) Chemical Communications 51: 12947-12949.

Rancan M, Carlotto A, Bottaro G et al. (2019) Inorganics 7: 103.

Roothaan CCJ (1951) Reviews of Modern Physics 23: 69-89.

Roy S, Banerjee S, Biyani N (2011) Journal of Physical Chemistry B 115: 685-692.

Samsonowicz M, Regulska E (2017) Spectrochimica Acta Part A: Molecular and Biomolecular Spectroscopy 173: 757-771.

Saytzeff A (1867) Ann Der Chem Und Pharm 144: $148-156$.

Sergievskii VV, Skorobogat'Ko DO, Rudakov AM (2010) Russian Journal of Physical Chemistry A 84: 350-355.

Šimunkova M, Lauro P, Jomova K et al. (2019) Journal of Inorganic Biochemistry 194: 97-113.

Šimunková M, Valko M, Bučinský L et al. (2020) J. Mol. Struct. 1222: 128923.

Singh Y, Ghosh T (2016) Talanta 148: 257-263.

Sládek V, Lukeš V, Breza M (2011) Computational and Theoretical Chemistry 963: 503-509.

Sudo R, Yoshioka D, Mikuriya M et al. (2012) X-Ray Structure Analysis Online 28: 71-72.

Tashrifi Z, Khanaposhtani MM, Larijani B et al. (2020) Advanced Synthesis and Catalysis 362: 65-86.

Tomasi J, Mennucci B, Cammi R (2005) Chem. Rev. 105: 2999-3093.

Tunçer S, Gurbanov R, Sheraj I et al. (2018) Scientific Reports 8: 14828.

Vosko SH, Wilk Nusair M (1980) Canadian Journal of Physics 58: 1200-1211. 


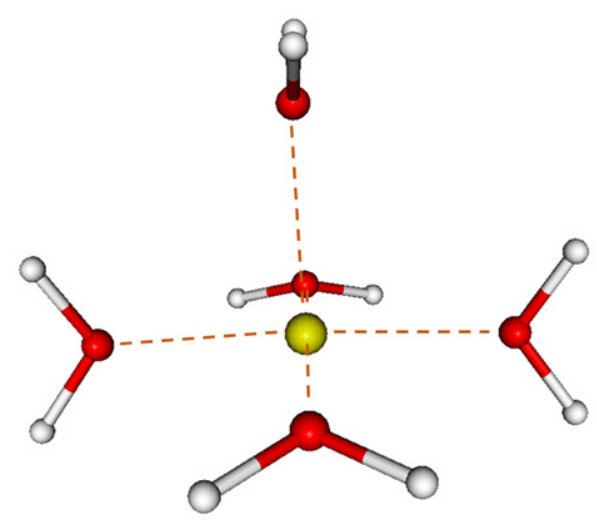

a)

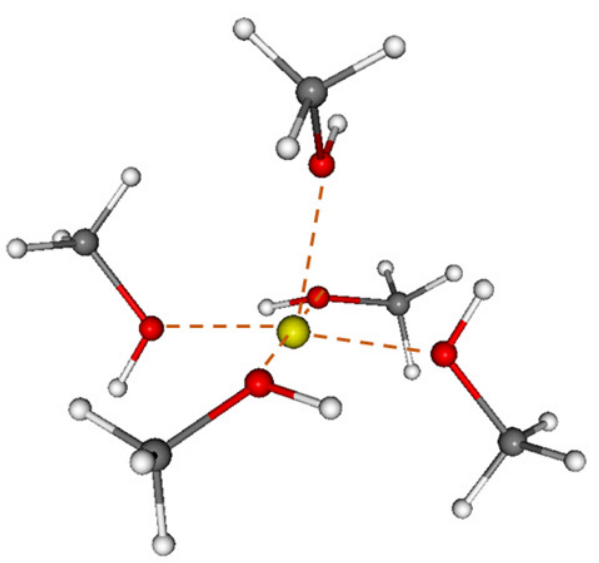

c)

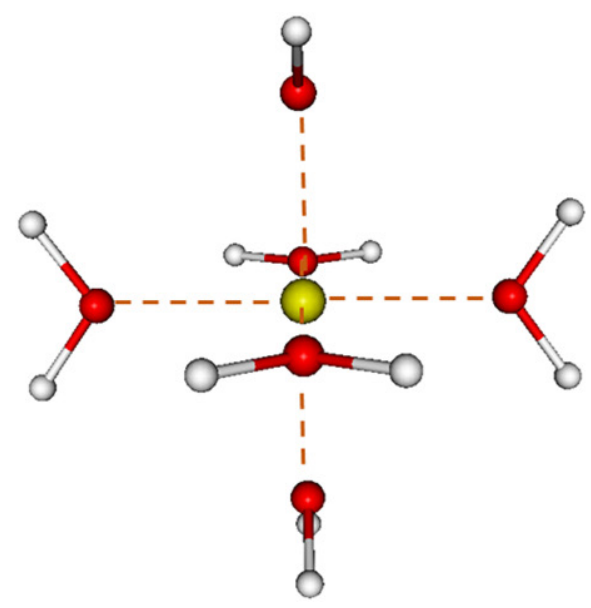

b)

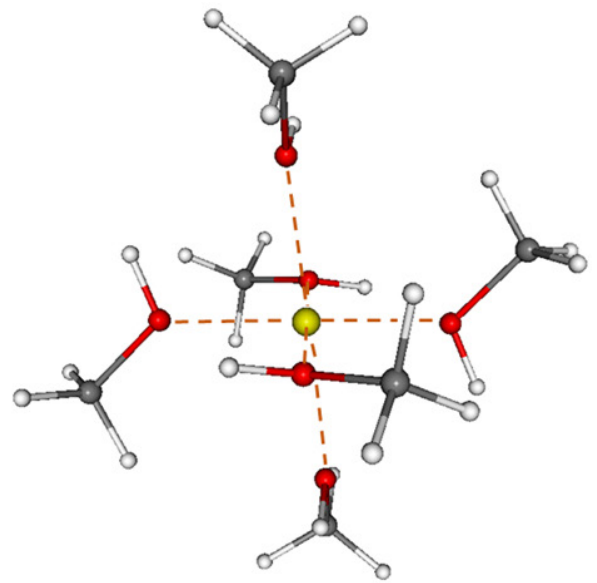

d)

Fig. S1 Scheme of B3LYP/6-311G*/PCM optimized reference systems: $\mathrm{Cu}(\mathrm{II})-5 \mathrm{H}_{2} \mathrm{O}(\mathrm{a}), \mathrm{Cu}(\mathrm{II})-6 \mathrm{H}_{2} \mathrm{O}(\mathrm{b})$, $\mathrm{Cu}(\mathrm{II})-5 \mathrm{MeOH}(\mathrm{c}), \mathrm{Cu}(\mathrm{II})-6 \mathrm{MeOH}(\mathrm{d})$.

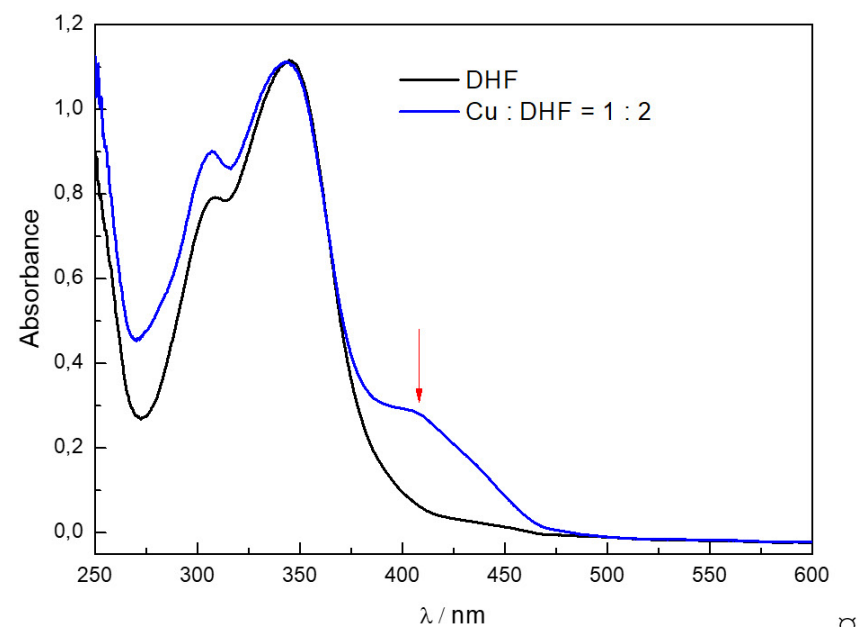

a)

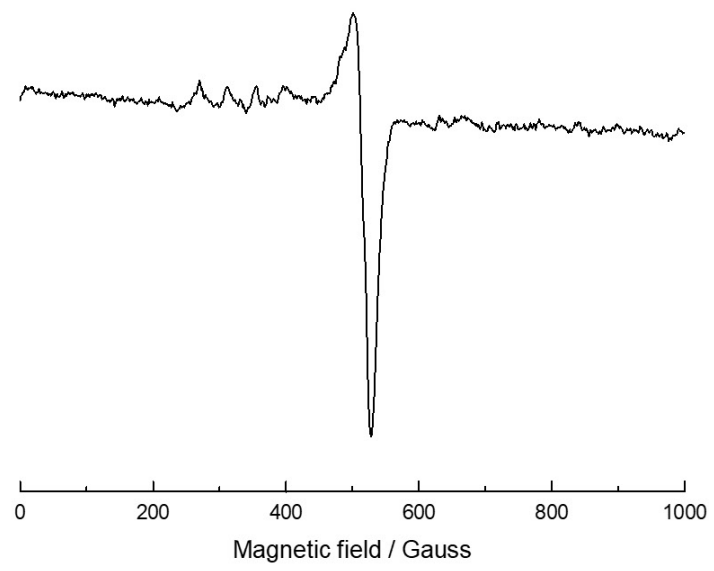

b)

Fig. S2 a) Black line: UV-Vis spectrum of DHF dissolved in methanol, c $=1.10^{-3} \mathrm{M}$; blue line: UV-Vis spectra of DHF-Cu(II) (molar ratio = 2:1) system measured in methanol b) EPR spectrum of DHF-Cu(II) $($ molar ratio $=2: 1)$ system dissolved in methanol measured at $120 \mathrm{~K}$ (experimental parameters: $\mathrm{g}_{\perp}=2,10$

$$
\mathrm{g}_{\|}=2,42 \mathrm{~A}_{\|}=102 \text { Gauss). }
$$


Tab. S1. Calculated B3LYP/6-311G*/PCM Cu-O bond lengths $(d)$, charge densities $\left(\rho_{\mathrm{BCP}}\right)$, Laplacians $\left(\Delta \rho_{\mathrm{BCP}}\right)$ and delocalization indexes (DI) of $\mathrm{Cu}(\mathrm{II})-n \mathrm{H}_{2} \mathrm{O}$ and $\mathrm{Cu}(\mathrm{II})-n \mathrm{MeOH}$ systems (where $n=5$, 6). Superscripts "E" or "A" stand for average values of equatorial or axial $\mathrm{Cu}-\mathrm{O}$ bonds, respectively.

\begin{tabular}{|c|c|c|c|c|}
\hline System & $d / \AA ̊ \AA$ & $\rho_{\mathrm{BCP}} /$ bohr $^{-3}$ & $\Delta \rho_{\mathrm{BCP}} /$ bohr $^{-5}$ & DI/- \\
\hline \multirow[t]{2}{*}{$\mathrm{Cu}-5 \mathrm{H}_{2} \mathrm{O}$} & $1.97^{\mathrm{E}}$ & $0.08^{\mathrm{E}}$ & $0.46^{\mathrm{E}}$ & $0.37^{\mathrm{E}}$ \\
\hline & $2.18^{\mathrm{A}}$ & $0.05^{\mathrm{A}}$ & $0.24^{\mathrm{A}}$ & $0.21^{\mathrm{A}}$ \\
\hline \multirow[t]{2}{*}{$\mathrm{Cu}-6 \mathrm{H}_{2} \mathrm{O}$} & $1.99^{\mathrm{E}}$ & $0.07^{\mathrm{E}}$ & $0.43^{\mathrm{E}}$ & $0.34^{\mathrm{E}}$ \\
\hline & $2.22^{\mathrm{A}}$ & $0.05^{\mathrm{A}}$ & $0.21^{\mathrm{A}}$ & $0.19^{\mathrm{A}}$ \\
\hline \multirow[t]{2}{*}{$\mathrm{Cu}-5 \mathrm{MeOH}$} & $1.98^{\mathrm{E}}$ & $0.08^{\mathrm{E}}$ & $0.44^{\mathrm{E}}$ & $0.37^{\mathrm{E}}$ \\
\hline & $2.22^{\mathrm{A}}$ & $0.05^{\mathrm{A}}$ & $0.20^{\mathrm{A}}$ & $0.19^{\mathrm{A}}$ \\
\hline \multirow[t]{2}{*}{$\mathrm{Cu}-6 \mathrm{MeOH}$} & $2.00^{\mathrm{E}}$ & $0.07^{\mathrm{E}}$ & $0.41^{\mathrm{E}}$ & $0.35^{\mathrm{E}}$ \\
\hline & $2.27^{\mathrm{A}}$ & $0.04^{\mathrm{A}}$ & $0.17^{\mathrm{A}}$ & $0.17^{\mathrm{A}}$ \\
\hline
\end{tabular}

Tab. S2. Mulliken and QTAIM charges $(q)$ at $\mathrm{Cu}, \mathrm{H}_{2} \mathrm{O}$ and $\mathrm{MeOH}$ moieties calculated at the B3LYP/6$311 G^{*} /$ PCM level of theory. Superscripts "E" or "A" indicate the position (equatorial or axial, respectively) of the $\mathrm{H}_{2} \mathrm{O}$ or $\mathrm{MeOH}$ molecules.

\begin{tabular}{llccc}
\hline System & & $q(\mathbf{C u}) / \boldsymbol{e}$ & $\boldsymbol{q}$ (solvent) $)^{\mathrm{E}} / \boldsymbol{e}$ & $\boldsymbol{q}(\mathbf{\text { solvent }})^{\mathrm{A}} / \boldsymbol{e}$ \\
\hline $\mathrm{Cu}-5 \mathrm{H}_{2} \mathrm{O}$ & Mulliken & 1.51 & 0.11 & 0.06 \\
& QTAIM & 1.43 & 0.12 & 0.05 \\
$\mathrm{Cu}-6 \mathrm{H}_{2} \mathrm{O}$ & Mulliken & 1.56 & 0.09 & 0.04 \\
& QTAIM & 1.45 & 0.11 & 0.05 \\
$\mathrm{Cu}-5 \mathrm{MeOH}$ & Mulliken & 1.47 & 0.12 & 0.04 \\
& QTAIM & 1.40 & 0.14 & 0.05 \\
$\mathrm{Cu}-6 \mathrm{MeOH}$ & Mulliken & 1.56 & 0.09 & 0.04 \\
& QTAIM & 1.40 & 0.12 & 0.05 \\
\hline
\end{tabular}

